\title{
Overview of Multi-Layer Metal Insulation Development for Small Stirling Convertors at NASA GRC
}

\author{
Daniel D. Goodell ${ }^{1}$, Nicholas A. Schifer ${ }^{2}$, and Scott D. Wilson ${ }^{3}$ \\ NASA Glenn Research Center, Cleveland, Ohio, 44135, U.S.A.
}

\begin{abstract}
A small Stirling convertor is currently under development at the NASA Glenn Research Center (GRC) to produce one watt of electrical power from eight watts of heat. Previous radioisotope power systems (RPS) made use of the General-Purpose Heat Source (GPHS) which produces 250 watts of heat but is unsuitable for a one-watt Stirling convertor. The only other qualified heat source available is the Light-Weight Radioisotope Heating Unit (LWRHU), which produces one watt of heat and is primarily used to provide heat to electronics and instrumentation to maintain their appropriate operating temperature. Unfortunately, the LWRHU has a heat flux of $272 \mathrm{~W} / \mathrm{m}^{2}$ compared to the GPHS heat flux of $6000 \mathrm{~W} / \mathrm{m}^{2}$ which greatly increases the demands on the insulation to ensure that enough of the heat produced is available to the convertor and not lost to the environment. An analysis was performed that showed that the insulation must have an effective thermal conductivity of $0.005 \mathrm{~W} / \mathrm{m} \cdot \mathrm{K}$ or better for the system to function. A multi-layer metal insulation package was designed and a prototype was fabricated and tested to investigate the feasibility of this design. While the prototype did not meet the requirements perfectly, the lessons learned are being used to generate an improved thermal model using the test data so that a second iteration can developed that will meet the performance requirements with a much higher confidence.
\end{abstract}

\section{Introduction}

There is a need for a low-power radioisotope power system (RPS) to power small sensor packages and repeaters for use in deep space and other areas where solar power is unfeasible. A small Stirling convertor with a nominal electrical power output of one watt is being developed at the NASA Glenn Research Center (GRC) to meet this need. This convertor would require approximately 6.5 watts of heat to operate. There are only two space qualified heat sources available to provide heat for an RPS system: the general-purpose heat source (GPHS) and the light-weight radioisotope heating unit (LWRHU). The GPHS produces 250 watts of heat and is not suitable for a one-watt power system. The LWRHU produces one watt of heat so multiple units could be used to provide the required heat input to the convertor. The GPHS was designed to provide heat to a radioisotope thermoelectric generator (RTG) to temperatures greater than $1000{ }^{\circ} \mathrm{C}$ and has a heat flux through its surface of approximately $6000 \mathrm{~W} / \mathrm{m}^{2}$. The LWRHU was designed to supply auxiliary heat to electronics and only provides $272 \mathrm{~W} / \mathrm{m}^{2}$. The large surface area of the LWRHU relative to the power output puts greater demands on the insulation, requiring a lower effective thermal conductivity then that used by GPHS-based systems to minimize the heat loss. Previously used insulation includes Microtherm ${ }^{\circledR}$ HT with a thermal resistance of approximately $0.02 \mathrm{~W} / \mathrm{m} \cdot \mathrm{K}$. Analysis of a proposed LWRHU heat source and convertor shows that the insulation must have a thermal conductivity of approximately $0.005 \mathrm{~W} / \mathrm{m} \cdot \mathrm{K}$ [1] to ensure that enough heat is provided to the convertor.

\section{Design \& Fabrication}

It was determined that a prototype insulation assembly that utilized all the dimensions, features, and interfaces of the final convertor system should be developed so that any unexpected difficulties in the implementation could be found as early in the development process as possible. Previous work on a similar insulation intended for use in the

${ }^{1}$ Engineer, Thermal Energy Conversion Branch, not an AIAA member.

${ }^{2}$ Engineer, Thermal Energy Conversion Branch, not an AIAA member.

${ }^{3}$ Engineer, Thermal Energy Conversion Branch, not an AIAA member. 
Advanced Stirling Radioisotope Generator (ASRG) project discovered some difficulties during the manufacturing and testing that had not been foreseen. [2] The prototype Stirling convertor mechanical design was complete prior to beginning the insulation design process, therefore, all the mechanical dimensions of the insulation package could be designed to be compatible with the Stirling prototype. Additionally, although the prototype will be dimensionally accurate, some expensive and time-consuming features may be omitted so that the manufacturing basic performance could be understood. The inexpensive first prototype is not expected to meet all the performance requirements; however, the knowledge gained will allow for a second, higher-fidelity, prototype that will have a high probability of achieving the required effective thermal conductivity.

Early in the design process, the insulation prototype was divided into three physical components that were manufactured and designed separately and integrated into the final test package:

1. The thermal simulator, to simulate the operating Stirling convertor and its thermal and physical interfaces/

2. The heat source, which will electrically simulate the eight LWRHUs that are proposed as the heat source

3. The insulation package, which contains several layers of closely spaced low emissivity titanium foils suitable for pumping down to a vacuum and containing the necessary mounting points for the heat source and the thermal simulator.

\section{A. Thermal simulator}

The thermal simulator, shown in Fig. 1, was designed and manufactured by NASA with the same dimensions and thermal conductivity of the Stirling convertor at the design hot-end temperature of $350{ }^{\circ} \mathrm{C}$. Additionally, the ability to measure the hot-end temperature and heat flow through the thermal simulator was considered necessary to understand how much heat is lost through the convertor versus how much is consumed by the convertor. To accommodate the requirement of having the same dimensions and thermal conductivity as the real Stirling convertor, the simulator was designed in two parts. An outer shell of higher thermal conductivity 410 stainless steel and an inner rod of Inconel ${ }^{\circledR}$ 625 with lower thermal conductivity. The thermal simulator was designed to have the same thermal conductivity as the operating Stirling convertor by adjusting the ratio of cross-sectional areas for the shell and the rod. Four equallyspaced thermocouples were added to the rod to allow for the heat flow through the thermal simulator to be calculated via Fourier's law.

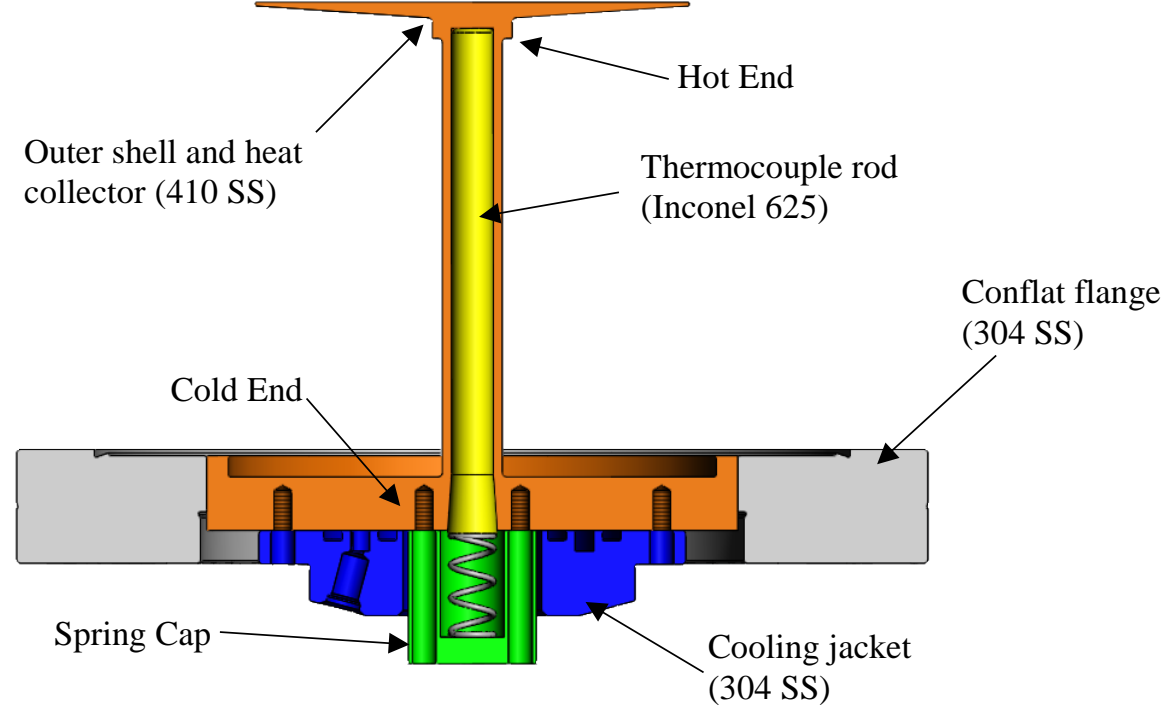

Figure 1. Cross-section of the thermal simulator.

An important feature of the insulation package that was defined early on was the interface between the heat source and the Stirling convertor. The prototype Stirling convertor was designed to have the minimum practical wall thickness to limit thermal conduction losses; however, this thin wall limits the ability of the Stirling convertor to support mechanical loads. The heat source was designed to be radiatively coupled to the Stirling convertor to prevent the heat source from causing any additional mechanical load on the Stirling convertor. The radiative coupling will result in slightly higher heat source temperatures than a direct conductive coupling which will increase the demands on the insulation. The thermal simulator was fitted with an $81 \mathrm{~mm}$ (3.19") diameter heat collector plate. The heat collector plate was grit blasted to increase the emissivity and to provide the necessary surface for the radiative heat transfer. The emissivity of a representative sample of 410 stainless steel was measured at approximately 0.55 . A ConFlat ${ }^{\circledR}$ 
flange was welded to the outside of the thermal simulator so that it could be disassembled from the insulation test package allowing for inspection, modification, or replacement of internal components.

\section{B. Electrical Heat Source}

The electrical heat source show in Figure 2 was designed at NASA GRC to simulate the dimensions, heat produced, and thermal properties of the eight LWRHUs. The electrical heat source was designed to have approximately the same outer dimensions as eight LWRHUs arranged in two stacks of four as shown in Figure 3. Arranging the LWRHUs in this manner allows the insulation package outer diameter to be no larger than the diameter of the Stirling convertor. The core of the heat source is a machined piece of POCO ${ }^{\circledR}$ AXF-5Q graphite which has similar thermal properties to the outer shell of the LWRHU. The block contains four holes to accommodate 3/8” (9.525 mm) diameter cartridge heaters. Hermetically-sealed cartridge heaters were chosen to limit the potential for outgassing and reduce pump-down times. Two circular bus bars that were made from nickel 201 were welded to the cartridge heater leads to provide electrical contact. The graphite block is slightly longer than the LWRHUs to accommodate the electrical connections to the cartridge heaters.

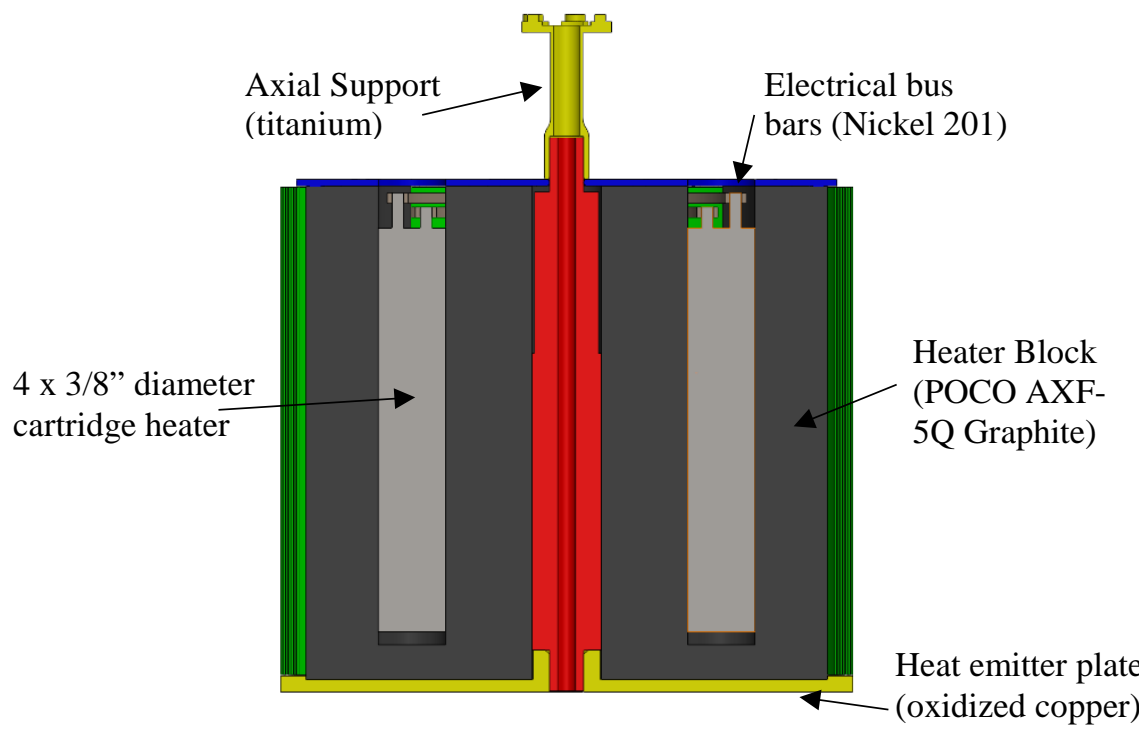

Figure 2. Cross-section of the electrical heat source.

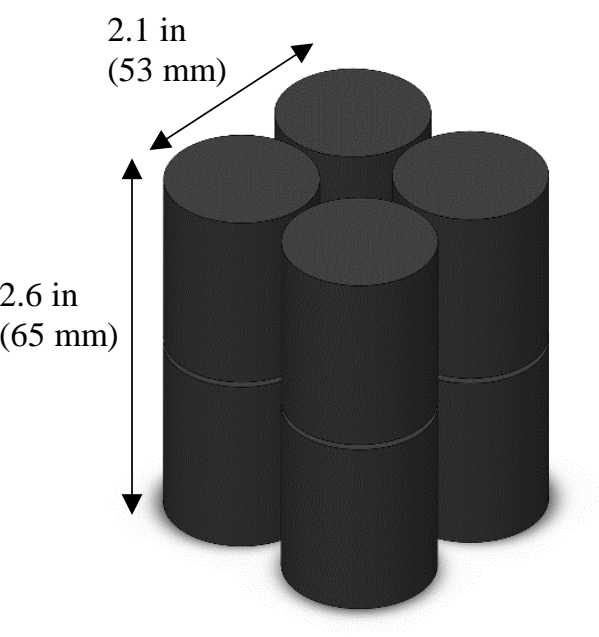

Figure 3. Arrangement of 8 LWRHUs used as heat source. Total mass is $160 \mathrm{~g}$.

At the bottom of the heat source is an oxidized copper plate that will radiate heat to the heat collector plate on the thermal simulator. The oxidized copper surface has an estimated emissivity of 0.88 . There are several small hemispherical bumps around the perimeter of the emitter plate that will provide point contacts against the inner layer of the insulation package. These features will radially constrain the heat source in the insulation package resulting in the minimum thermal conduction from the heat source to the insulation. At the top of the electrical heat source is a thin titanium tube which will attach to the inner surface of the insulation. This tube will provide axial support to the heat source and maintain the correct spacing of the emitter plate and the thermal simulator.

\section{Insulation Package}

The final insulation package is shown in Figure 4. It was designed and manufactured by Peregrine Falcon Corp. of Pleasanton, CA. The design and fabrication of the cylindrical insulation canister and final integration of the GRC provided heat source and thermal simulator were accomplished at Peregrine prior to being sent to GRC for testing. The insulation is made of ten layers of 0.010 ” $(0.254 \mathrm{~mm})$ thick titanium foils separated by a 0.005 ” $(0.127 \mathrm{~mm})$ diameter wire. Only approximately one-and-a-half turns of this wire were used between each of layer of titanium in the cylindrical section to minimize direct conduction losses through the wire. A cylinder of thicker stainless steel was used as the innermost layer to provide structural support to the inner components. The outer shell of the insulation assembly was made from thicker stainless steel and functions as a vacuum vessel that can be evacuated to provide the low gas density that is necessary for the operation of the insulation. A ConFlat ${ }^{\circledR}$ flange that mates with the thermal simulator was welded to the end of the outer shell. A feed-through for the heat source electrical power and four 1/16" 


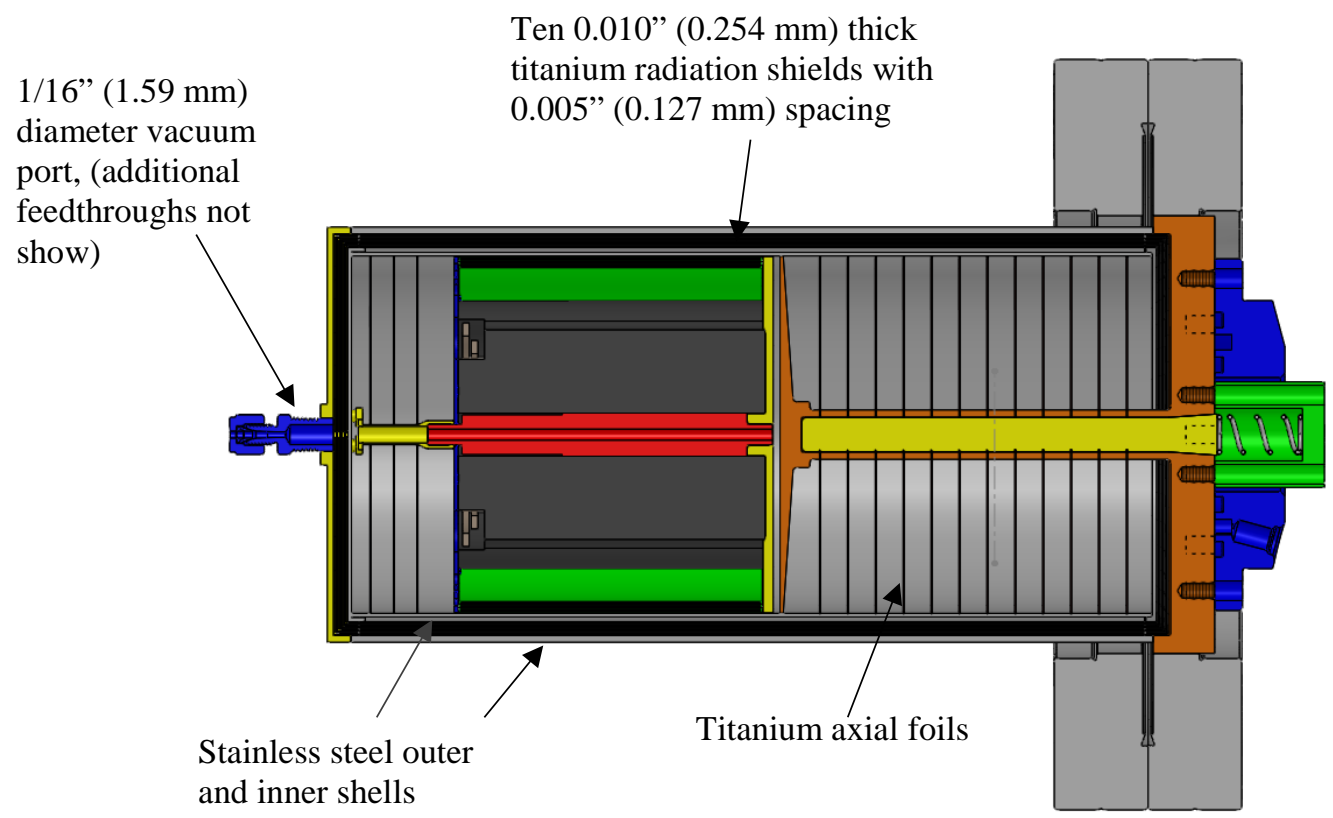

Figure 4 - Cross section of the full insulation assembly.

(1.59 mm) Swagelok ${ }^{\circledR}$ fittings were welded into the end-cap to provide a port to connect to a vacuum pump and to accommodate three type-K thermocouples used to monitor the temperature of the heat source and adjacent areas during testing.

A feature that was omitted from the first prototype but is expected to be necessary for the insulation package to meet the low thermal conductivity requirements is the polishing and vapor deposition of gold onto the titanium foils. The polished gold surface would significantly lower the emissivity of the surface and reduce the heat lost through radiation. This feature would have added time and expense and it was considered a higher priority to understand the conductive losses and manufacturability of the insulation. The impact of reducing the emissivity of the titanium shields is predictable and easily modeled, while many of the conductive losses are through point and line contacts and difficult to model accurately.

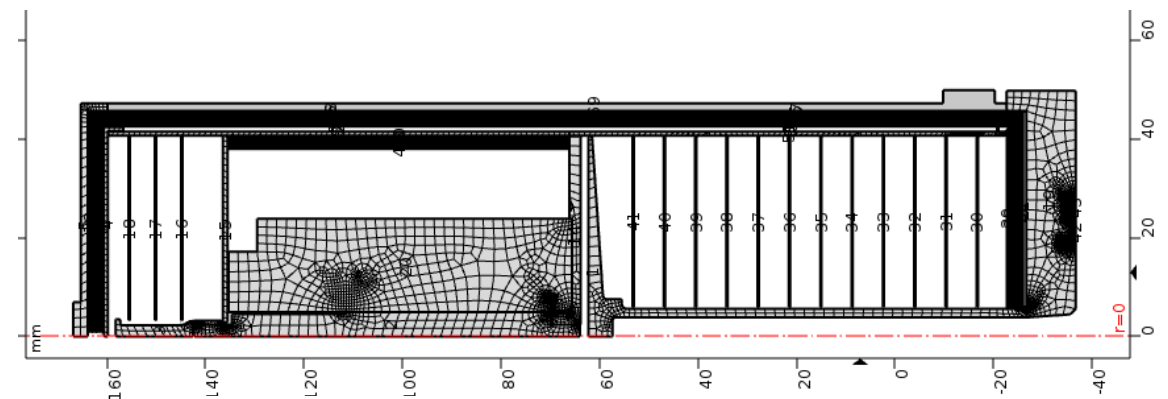

Figure 5 - Axisymmetric Model used for the Thermal Analysis.

\section{Modeling and Analysis}

During the manufacturing of the insulation package, Vantage Partners LLC. Of Brook Park, Ohio, performed a thermal analysis of the insulation package design to predict its performance. The analysis was performed using a simplified axisymmetric model of the insulation using COMSOL Multiphysics ${ }^{\circledR}$ 5.3a. The simplified model did not include most of the conductive losses through the insulation; however, all the radiative features were included. Several cases were run at different ambient conditions and different titanium shield emissivities. A few cases were run omitting some features of the insulation, such as the axial shields around the thermal simulator or the radiative gap between the emitter and collector plates. Table 2 in the appendix shows a summary of the results of this initial analysis. The analysis shows that the insulation has the potential to meet the requirements if the titanium shield emissivity is sufficiently 
low. Additional cases of the model will be run in conjunction with the testing to help understand the magnitude of the conductive and radiative losses through the shields.

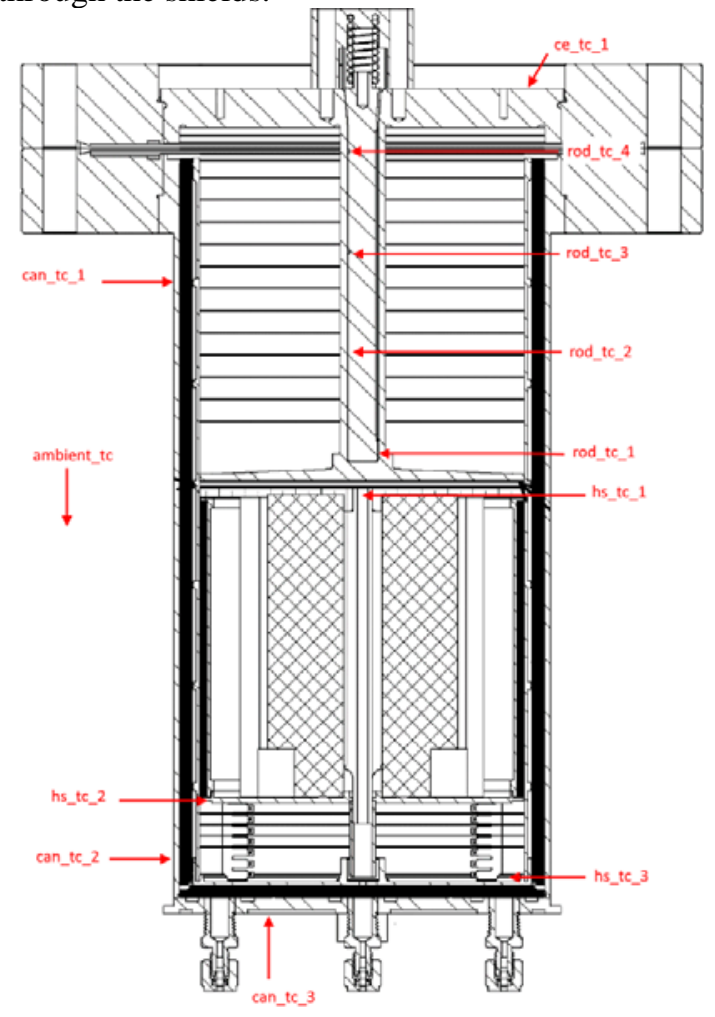

Figure 6. Thermocouple Locations

\section{IV.Testing}

Peregrine Falcon Corp. completed the assembly of the insulation and integration of the heat source and thermal simulator. They also performed basic testing to ensure that the vacuum vessel did not leak and that all the electrical feedthroughs were functional. Afterward, the insulation package was sent to NASA GRC to install the remainder of the test instrumentation, integrate it into the test hardware, and complete the testing. Thermocouples were installed in the thermocouple rod and several additional surface mount thermocouples were added to the outside of the insulation canister and the cold end of the thermal simulator (Figure 6). Tgon ${ }^{\mathrm{TM}} 800$ was placed at the tip of the thermocouple rod and a thermal grease was placed at the cold-end interface to ensure that good thermal contact was made. A cooling jacket was attached to the cold end of the thermal simulator and plumbed to a refrigerated circulator to precisely control the cold-end temperature using distilled water as a coolant. The heat source was connected to a DC power supply that was controlled by a PID temperature controller that used the rod thermocouple as feedback. This allows the hot and cold-end temperatures of the thermal simulator to be adjusted so that several data points can be gathered to determine the insulation performance. The $1 / 16$ " feedthrough was connected to an oil-free turbo-molecular pumping station and used to evacuate the insulation package prior to testing and to monitor the vacuum level during testing.

During the initial pump down of the insulation, it was realized that the $1 / 16$ " diameter feedthrough size resulted in longer pump-down times. It was estimated that it would take several days for the insulation to be evacuated to $10^{-4}$, torr which was considered sufficient to accomplish the testing. The insulation was evacuated for four days prior to the initial heating. After heating to $100{ }^{\circ} \mathrm{C}$ the insulation outer canister temperatures reached nearly $50{ }^{\circ} \mathrm{C}$. This indicated that the performance was not reaching the levels that were anticipated for the prototype. It was uncertain whether the insulation was not evacuating properly, or if there was some other reason for higher heat loss than anticipated. The insulation was allowed to evacuate for two more weeks. Additional discussions with the vendor revealed that the cylindrical titanium foils required heat treatment to relieve stress during manufacturing and despite taking place in an inert gas atmosphere, the titanium shields were oxidized. Unoxidized titanium has an anticipated emissivity of approximately 0.1 while oxidized titanium is expected to have an emissivity of 0.6 . This oxidation was not removed prior to final assembly and had a major impact on the performance of the insulation. 
Following a two-week pump down, the insulation was heated again to gather data. Upon heating significant outgassing occurred. This required additional waiting periods of several days before the level recorded by the vacuum pump returned to the original level. Because the insulation performance was below expectations, the thermal simulator was also not able to be heated to the $350{ }^{\circ} \mathrm{C}$ operating temperature of the Stirling convertor. Data was taken at the highest power level and temperatures that were considered safe for the insulation package. The preliminary results of the evacuated thermal testing are show in Table 1.

Table 1 - Initial results of the insulation testing

\begin{tabular}{|l|l|}
\hline & Units \\
\hline & \\
\hline hs_tc_1 & C \\
\hline hs_tc_2 & C \\
\hline hs_tc_3 & C \\
\hline can_tc_1 & C \\
\hline can_tc_2 & C \\
\hline can_tc_3 & C \\
\hline rod_tc_1 & C \\
\hline rod_tc_2 & C \\
\hline rod_tc_3 & C \\
\hline rod_tc_4 & C \\
\hline ce_tc_1 & C \\
\hline ce_tc_2 & C \\
\hline ambient_tc & C \\
\hline heater voltage & V \\
\hline heater current & A \\
\hline heater power & W \\
\hline Heat through TC Rod (calc.) & W \\
\hline Radiative heat flow from heat source to thermal simulator (calc.) & W \\
\hline Heat loss through insulation (calc.) & W \\
\hline Percent Heat through Insulation & W \\
\hline
\end{tabular}

\section{Conclusion}

Although the insulation package did not perform as originally expected, several lessons were learned that will help in the design and testing of the second iteration that has a better probability of achieving the performance required. First is that the $1 / 16$ " diameter port needs to be increased to achieve a better vacuum and reduce pump down times. A much larger port should be installed for future testing. A measurement of the vacuum level inside the insulation package is desirable if it is possible to implement without a significant impact on the insulation performance so that 
the vacuum level can be verified. Additionally, the emissivity of the titanium shields is critical and if it is too high it could compromise the insulation package. These emissivities should be measured during fabrication to ensure that they meet requirements.

There are several options for the next steps in the testing of this insulation package. The insulation can be disassembled and the emissivities of the various internal components can be measured to provide additional data so that the thermal model can be updated. The existing test package could be disassembled and the oxidation could be chemically removed from the titanium shields and then reassembled to improve their emissivity. Additional testing can be done to measure the impacts of the improvement in this emissivity on performance of the insulation package.

For the next design iteration, the improved thermal model could be used to help give accurate targets for several design features with a much higher confidence level. Resulting predictions of the conductive and radiative losses will be used to optimize the number of layers of titanium foil required and allow the appropriate emissivity for the titanium shields to be determined. The thickness and design of the inner structural layer will also be optimized to reduce thermal losses from the heat source to the cold-end of the thermal simulator. These improvements should result in an insulation package that meets the thermal design requirements of the proposed one-watt Stirling generator system. 


\section{Appendix}

Table 2 - Results of the initial thermal analysis

\begin{tabular}{|c|c|c|c|c|c|c|c|c|c|c|c|c|}
\hline 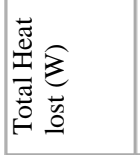 & $\begin{array}{l}\text { Iิ } \\
7 \\
\infty\end{array}$ & $\begin{array}{l}\approx \\
\stackrel{\infty}{\infty} \\
\infty\end{array}$ & $\begin{array}{l}-1 \\
\infty \\
\infty\end{array}$ & $\begin{array}{l}\infty \\
\infty \\
\infty \\
\infty\end{array}$ & $\begin{array}{l}\infty \\
\infty \\
\infty\end{array}$ & $\stackrel{m}{\infty}$ & $\begin{array}{l}\hat{O} \\
\infty \\
\infty\end{array}$ & 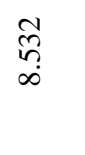 & 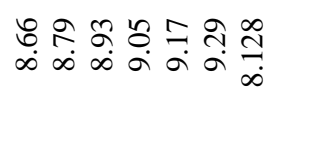 & $\begin{array}{l}\stackrel{0}{ } \\
\text { o } \\
\stackrel{0}{N} \\
\end{array}$ & $\underset{\infty}{\infty}$ & 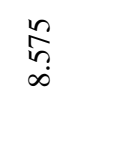 \\
\hline 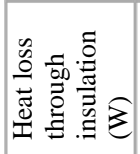 & ָे & 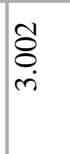 & $\underset{\substack{1 \\
\infty \\
\infty}}{1}$ & $\begin{array}{l}\infty \\
\infty \\
\infty \\
\infty\end{array}$ & $\begin{array}{l}\infty \\
\infty \\
\infty\end{array}$ & 0 & ○ & $\begin{array}{l}\text { ָे } \\
\text { లె. } \\
0\end{array}$ & 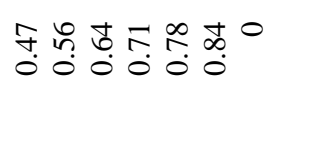 & $\begin{array}{l}0 \\
\infty \\
\infty \\
\infty \\
0 \\
0\end{array}$ & $\stackrel{\mathscr{T}}{+}$ & $\begin{array}{l}\stackrel{1}{\hat{~}} \\
\stackrel{0}{0}\end{array}$ \\
\hline 总总 & 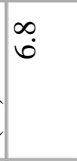 & $\ddot{m}$ & 0 & 0 & 0 & $\underset{\infty}{\infty}$ & 命 & $\stackrel{\hat{\imath}}{\infty}$ & 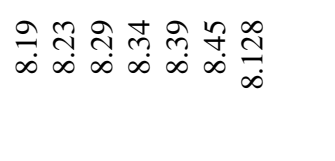 & 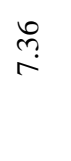 & $\stackrel{\leftrightarrow}{\leftrightarrow}$ & $\stackrel{\Omega}{\wedge}$ \\
\hline 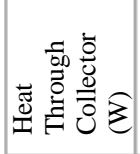 & సิ & $\hat{\hat{N}}$ & $\begin{array}{l}\text { ลิ } \\
0 \\
\varphi\end{array}$ & $\begin{array}{l}\infty \\
\infty \\
1 \\
\text { ம் }\end{array}$ & $\begin{array}{l}\text { Lू } \\
\text { ம் }\end{array}$ & $\underset{\substack{\sim \\
\emptyset}}{ }$ & 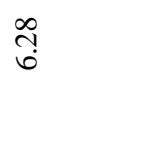 & $\stackrel{m}{\sim}$ & 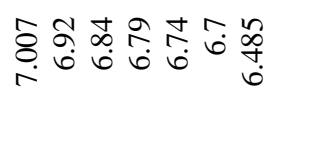 & $\mathscr{\mathscr { H }}$ & $\stackrel{\text { लै }}{6}$ & $\begin{array}{l}\mathscr{\Xi} \\
\dot{0}\end{array}$ \\
\hline 总 & $\begin{array}{l}\bar{m} \\
\ddot{m} \\
\dot{m} \\
m\end{array}$ & 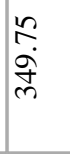 & 通 & \& & $\underset{f}{\stackrel{f}{f}}$ & $\begin{array}{l}\infty \\
\vdots \\
\stackrel{N}{\tilde{m}} \\
\text { }\end{array}$ & $\begin{array}{l}\llcorner \\
\infty \\
\stackrel{\sim}{\infty} \\
\text { mे }\end{array}$ & 芦 & 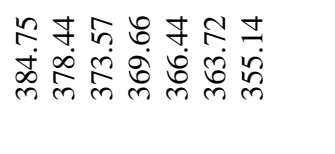 & ঙे & $\begin{array}{l}\stackrel{m}{+} \\
\stackrel{D}{\sim}\end{array}$ & $\begin{array}{l}\stackrel{\rho}{1} \\
\infty \\
o \\
\&\end{array}$ \\
\hline 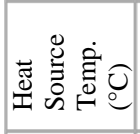 & $\begin{array}{l}0 \\
\infty \\
\infty \\
\infty \\
\infty\end{array}$ & $\begin{array}{l}\text { Un } \\
\text { in } \\
\infty \\
m\end{array}$ & 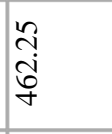 & 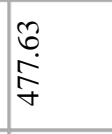 & ঙ্ণ & 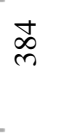 & 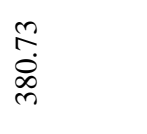 & 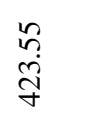 & 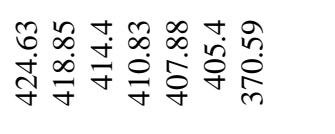 & 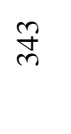 & 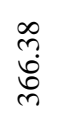 & $\begin{array}{l}\bar{b} \\
\dot{\dot{m}} \\
\dot{\gamma}\end{array}$ \\
\hline 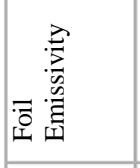 & ô. & $\stackrel{1}{0}$ & $\stackrel{\circ}{\circ}$ & $\stackrel{1}{\circ}$ & $\stackrel{1}{\circ}$ & $\stackrel{\hat{o}}{\circ}$ & $\stackrel{\circ}{\circ}$ & $\stackrel{+}{0}$ & 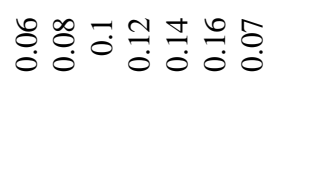 & $\stackrel{\circ}{\circ}$ & $\stackrel{\circ}{\circ}$ & $\stackrel{\circ}{0}$ \\
\hline 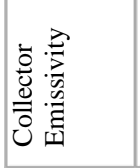 & นึ & L & 岗 & 岇 & 占 & 㞫 & 占 & 岇 & 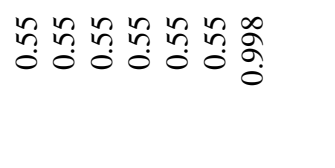 & * & 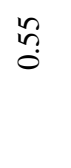 & 占 \\
\hline 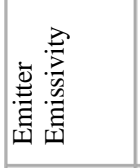 & $\begin{array}{l}\infty \\
\infty \\
\infty \\
0\end{array}$ & $\stackrel{\substack{\infty \\
\infty \\
0}}{0}$ & $\begin{array}{l}\infty \\
\infty \\
0 \\
0\end{array}$ & $\begin{array}{l}\infty \\
\infty \\
\infty \\
0\end{array}$ & $\begin{array}{l}\infty \\
\infty \\
0 \\
0\end{array}$ & $\begin{array}{l}\infty \\
\stackrel{\infty}{\infty} \\
\dot{0}\end{array}$ & $\begin{array}{l}\infty \\
\infty \\
0 \\
0\end{array}$ & $\begin{array}{l}\infty \\
\stackrel{0}{0} \\
\dot{0}\end{array}$ & 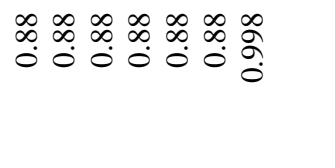 & $*$ & $\begin{array}{l}\infty \\
\infty \\
0 \\
0\end{array}$ & $\begin{array}{l}\infty \\
\infty \\
\infty \\
0\end{array}$ \\
\hline 节富 & จิ & શิ & $\stackrel{\text { }}{\stackrel{R}{1}}$ & จิ & in & & 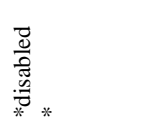 & 요 & 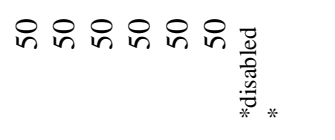 & 요 & จิ & ฉิ \\
\hline 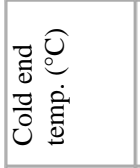 & in & 요 & 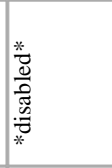 & 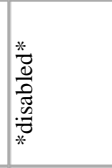 & 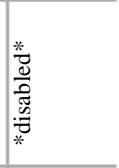 & 요 & 요 & 오 & 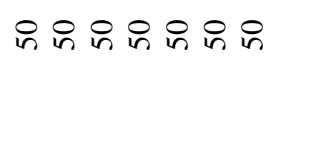 & 요 & $\stackrel{i}{ }$ & $*$ \\
\hline 苋 & 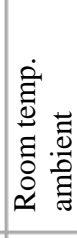 & 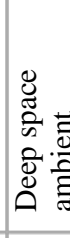 & 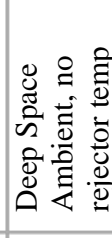 & 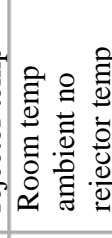 & 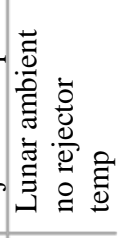 & 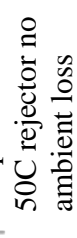 & 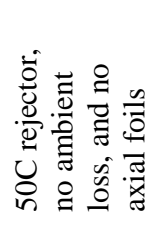 & 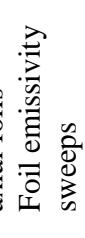 & 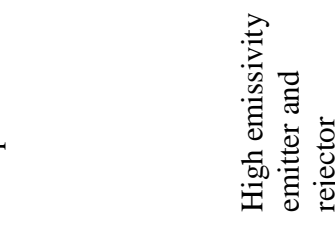 & & 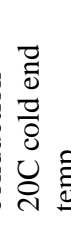 & 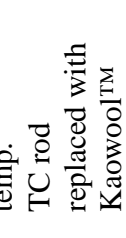 \\
\hline \# & - & N & $m$ & $\nabla$ & L & 0 & $\wedge$ & $\infty$ & 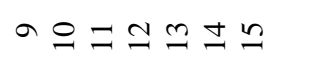 & $\underline{\sim}$ & $\approx$ & $\stackrel{\infty}{\sim}$ \\
\hline
\end{tabular}




\section{References:}

[1] Wilson, S.D., Geng, S.M., Penswick, L.B., and Schmitz, P., "Radioisotope Heater Unit-Based Stirling Power Convertor Development at NASA Glenn Research Center” NASA/TM-2018-219704 (AIAA 2017-4715), 2017. http://ntrs.nasa.gov

[2] Wilson, S.D., Schifer, N.A., Williams, Z.D., and Metscher, J.F. "Overview of Stirling Technology Research at NASA Glenn Research Center” NASA/TM-2016-218909 (AIAA-2015-3509), 2015 